\title{
Emergency Healthcare Commodities for Africa: A Review of Logistics Models, a Suggested Model and a Research Agenda
}

\begin{abstract}
Purpose - Enormous numbers of people suffer from the effects of disasters, and humanitarian crises in Africa, including medical and healthcare emergencies. International response to the 2014 to 2016 Ebola pandemic in West Africa vividly demonstrates the need for efficient and effective logistics and supply chain systems in bringing succor to vulnerable communities. This paper reviews the academic literature on logistics models for sourcing, delivery, and distribution of medical and healthcare products for humanitarian emergencies in Africa from 1990 to 2018. The paper suggests areas for further research and proposes an effective logistics model useful for international and national humanitarian organisations as well as public health authorities in Africa and developing areas.
\end{abstract}

Design/methodology/approach - The paper draws upon a structured comprehensive review of the academic literature on logistics and supply chain management, and a qualitative analysis of the literature.

Findings - The paper finds significant gaps in the body of logistics and supply chain management research on practical deployable logistics models for sourcing, delivery, and distribution of medical and healthcare products for humanitarian emergencies. The paper suggests a model worthy of consideration by humanitarian and disaster response stakeholders and public health authorities in developing countries.

Research limitations/implications - This is a literature review paper based only on a comprehensive literature research and analysis for the period 1990 to 2018 .

Social implications - This paper advocates for further research on appropriate models of logistics for the sourcing, delivery, and distribution of medical and healthcare products to enhance the basic human rights and dignity of vulnerable people in developing countries.

Originality/value - The paper contributes directly to policy on logistics, humanitarian aid, disaster management, public health and health security policy in developing countries including Africa.

Keywords - Global logistics; Healthcare logistics

Paper type - Review paper 


\section{Introduction}

Each year, millions of people worldwide are affected by disasters, underscoring the importance of effective relief efforts (EMDAT 2017). Almost 220 million people were affected each year between 2001 to 2016 and causing over US\$ 120 billion economic losses on average (EM-DAT, 2017). Natural disasters are often unpredictable and uncertain, and most African governments struggle to assist victims of disaster mainly due to lack of logistics expertise and preparation and lack of financial capital. Although, natural disasters such as floods and epidemiological disasters are unpredictable, nevertheless they can be prepared for, and preparation is crucial for efficient response and management (Oloruntoba and Ramaswami, 2018; Celik et al 2016).

Due to these reasons, offering timely and necessary aid to those in need through efficient humanitarian and healthcare supply chains is a major challenge and logistics plays a strategic role in this regard (Balcik et al., 2016; Dufour et al., 2018). One of the most critical tasks during humanitarian operations is the efficient and effective planning, execution and management of required logistics activities in the important area of emergency related healthcare.

Also, in today's interconnected world, infectious diseases can spread rapidly within and between countries and result in epidemiological disasters (Armstrong-Mensah and Ndiaye, 2018). The 2014-2016 Ebola epidemic in Guinea, Liberia, and Sierra Leone underscored the inability of countries with limited capacities and weak public health systems to respond effectively and on time to epidemics and outbreaks (Wolicki et al 2016; Armstrong-Mensah and Ndiaye, 2018).

To add to the complexity, healthcare commodities, vaccinations, medicines and other emergency medical relief have unique logistical requirements such as the management of temperature control and use by dates in transit and in storage (Comes et al. 2018). Furthermore, many African governments suffer from lack of coping capacity due to meagre available national resources to help vulnerable and affected populations whenever any type of humanitarian crisis occurs. Hence, there are often significant gaps between the required basic universal health care and what many African governments are financially able to provide to their populations (INFORM, 2015). As a result, the international community and 
international humanitarian organisations are often invited to provide international assistance as regards managing, sourcing, procuring, and distributing aid in any type of humanitarian emergency.

As multiple international and national humanitarian organizations are deployed when a crisis occurs, the coordination of their efforts induces major difficulties and challenges which may have serious consequences for those impacted, especially where logistics infrastructure is inadequate. (Buatsi and Mbohwa, 2014; Schulz and Blecken, 2010). Thus, there is need for a framework on sourcing, delivery, and distribution of medical and healthcare products for humanitarian emergencies in Africa and other developing countries as alluded to for example by Heaslip et al. (2018).

Thus, the purpose of this paper is to explore the strategic design of an efficient healthcare delivery management system to assist African national governments and national and international humanitarian relief organizations with the management of their logistical and healthcare challenges in emergencies.

In this paper, we review the logistics and supply chain literature to understand the state-ofthe-art in humanitarian logistics models for healthcare commodities in humanitarian emergencies in Africa. The paper reports on a qualitative review of humanitarian logistics models for healthcare commodities in humanitarian emergencies in Africa. The paper focuses on published humanitarian logistics models for sourcing, delivery, and distribution of medical and healthcare commodities for humanitarian emergencies in Africa from 1990 to 2018. The paper classifies the range of published logistics models for sourcing, delivery, and distribution of medical and healthcare products for humanitarian emergencies in Africa from 1990 to 2018; and proposes a model for sourcing, delivery, and distribution of medical and healthcare commodities. The paper's research questions were:

1. What is the range of published academic logistics models for sourcing, delivery, and distribution of medical and healthcare products for humanitarian emergencies in Africa from 1990 to 2018 ?

2. Which models are effective based on logistics performance criteria published in academic logistics journals? 
3. How can a flexible, adaptable high performing logistics model be developed to assist the development of humanitarian logistics for healthcare commodities in humanitarian emergencies in Africa?

The rest of the report is structured as follows: section 2 summarizes the background to and justification for the study. In section 3, we discuss the qualitative literature review method used to undertake the review and the research process deployed. In section 3, we discuss the keywords adopted and utilized, databases searched, numbers of articles found, and those selected and excluded. Section 4 is a synthesis and discussion of our findings and conclusions of the review while section 5 outlines and proposes a more effective logistics model for sourcing, delivery, and distribution of medical and healthcare products for humanitarian emergencies in Africa. Section 6 discusses how these findings may be disseminated to stakeholders in the frontlines of emergency healthcare provision in Africa and other developing regions. Section 7 is the summary and concludes the paper with suggestions for future research.

\section{Background and justification to the study}

This paper is an outcome of a larger collaborative research project funded by the Humanitarian Innovation Initiative (HI2), Watson Institute of International and Public Affairs at Brown University, Providence, Rhode Island. The project emerged out of the aftermath of the logistical and supply chain challenges encountered by the World Health Organization-led (WHO) international multi-organizational medical relief response to the widespread transmission of the Ebola Virus Disease (EVD) in the West African countries of Guinea, Liberia and Sierra Leone (CDC, 2017).

On March 23, 2014, the WHO reported cases of Ebola Virus Disease (EVD) in the forested rural region of south-eastern Guinea. These early reports marked the beginning of the largest and most fatal epidemic of EVD in history (CDC, 2017). The virus soon spread to Guinea's capital city of Conakry, and on March 13, 2014, the Ministry of Health in Guinea issued an alert for an unidentified illness. Shortly after, the Pasteur Institute in France confirmed the illness as EVD caused by Zaire Ebola virus. On March 23, 2014, with 49 confirmed cases and 29 deaths, the WHO officially declared an outbreak of EVD (CDC, 2017).

Inadequate public health infrastructure and weak surveillance systems contributed significantly to the rapid spread of the disease to Guinea's neighboring countries, Liberia and Sierra Leone (Save the Children, 2015; Wolicki et al.2016). By July 2014, the outbreak spread to the densely 
populated urbanized capital cities of all three countries. Thus, providing an unprecedented opportunity for transmission. On August 8, 2014, WHO declared the deteriorating situation in West Africa a Public Health Emergency of International Concern (PHEIC), which is designated only for events with a risk of potential international spread or that require a coordinated international response (CDC, 2017).

Over the duration of the epidemic, EVD eventually leaped across West African land borders and the Mediterranean and Atlantic Oceans to seven additional countries: Italy, Mali, Nigeria, Senegal, Spain, the United Kingdom, and the United States. Ultimately, by the time the ten affected countries were declared Ebola-free two years later, on March 29, 2016, and the WHO lifted the PHEIC status on West Africa's Ebola situation; total worldwide suspected cases stood at 28,652, laboratory-confirmed cases stood at 15,261, and total deaths stood at 11,325 (Kaner and Schaak, 2016). The financial cost of the international medical relief response in the three countries where EVD first emerged has been estimated at USD 4.3 billion which is 15 times the annual national health budgets of the three countries of Guinea, Liberia and Sierra Leone combined (Save the Children, 2015).

The US-based Centers for Disease Control and Prevention in Atlanta (CDC) activated its Emergency Operations Center in July 2014 to help coordinate technical assistance and disease control activities with multiple international and local partners, governments and organizations in the six affected West African countries of Guinea, Liberia, Sierra Leone, Mali, Nigeria and Senegal (CDC, 2017). CDC personnel deployed to West Africa to assist with pandemic disaster response efforts such as surveillance, contact tracing, data management, laboratory testing, and health education. CDC staff also provided support with logistics, staffing, communication, analytics, and management.

Travelers leaving West Africa were screened at airports, to prevent cross-border transmission. Exit screening helped identify those at risk for EVD and prevent the spread of the disease to other countries. The US and many other countries also implemented enhanced entry screening for travelers arriving from Guinea, Liberia, Sierra Leone, and Mali by routing them to designated airports better able to assess travelers for risk (CDC, 2016). The scope of the outbreak regarding cases and geography has variously been attributed to weak national health systems and poor surveillance and reporting systems (Save the Children, 2015; Wolicki et al. 2016). 
WHO defines a health system as all the people, resources, policies and activities whose primary purpose is to promote and maintain health (Stoddart and Evans, 2017). WHO identifies six interrelated components of a health system: the health workforce; financing; equipment, medicines and supplies; the delivery of services; data and information systems; and the way the system is governed (WHO). Others reasons identified for such a catastrophic pandemic include unprecedented circulation of EVD in crowded urban areas (CDC, 2017), increased cross-border travels (Bradshaw, 2017; Galvani et al 2017), and tensions between prevailing cultural and traditional practices in West Africa and infection control practices (Jalloh et al. 2017).

A significant number of logistical challenges have equally been noted and is one of the six interrelated components of a healthcare system as defined by WHO (WHO, 2006). These logistics and SCM issues include lack of access to equipment, medicines, and supplies which is of utmost concern to us as logistics and SCM scholars. Others include a lack of logistics preparedness plans in those affected countries in West Africa (Wolicki et al. 2016), and at a broader level internationally -the inadequacy of the logistics of public health surveillance at local health districts as well as port health/quarantine at border posts (International Border Team Website, 2018).

Such low caliber logistics and supply chain systems have proven unable to respond rapidly in an emergency to outbreaks of diseases and pandemics (Save the Children, 2015; Wolicki et al. 2016). Moreover, in Guinea, Liberia, and Sierra Leone shortage of the equipment, staff, drugs, and health facilities needed to implement effective basic healthcare and infection-control measures are lacking (Save the Children, 2015; Wolicki et al. 2016). Indeed, more often than not, essential life-saving medicines and equipment are often unavailable, expensive, physically inaccessible, or of poor quality (McCoy, 2008; Save the Children, 2015).

Logistical issues have also been blamed on why the international community was so slow to see and act on what was happening in West Africa, and why potential Ebola vaccines and treatments were left on the shelf for years and not pursued for trial and commercialization (CDC, 2016, CDC, 2017). It is because of some of these logistical and other challenges that in March 2017 competitive grant funding was made available by HI2 and its partners to multidisciplinary groups of US and international scholars. The authors are recipients of a grant to undertake a qualitative review of humanitarian logistics models for healthcare commodities in humanitarian emergencies in Africa. 
[Type here]

\section{Qualitative literature review method}

Qualitative literature reviews often follow six steps: (1) defining the research question and study goals (2) determining the required characteristics of primary studies to be reviewed (3) retrieving a sample of potentially relevant literature (4) selecting the relevant literature, (5) synthesizing the literature and (6) reporting the findings and results (Tranfield et al 2003; Overstreet and Hazen, 2016; Durach et al. 2017; Koufteros et al 2018). Hence, section 3 of the paper comprises a description of the structured qualitative literature review methodological steps that we have undertaken in bringing the research to successful attainment of its broader goals. Section 3 comprises sub-sections on adopted keywords (sub-section 3.1); databases searched, and articles found (sub-section 3.2), and studies selected for inclusion and exclusion (sub-section 3.3). Section 3 concludes with sub-section 3.4 that summarizes the research process was undertaken (see Figure 1).

\subsection{Adopted keywords and search strategy}

The search strategy involved the identification and selection of a comprehensive set of keywords (28 keywords) (Tables $1 \& 2$ ) each of which was in turn inserted into each search engine and searched in the titles, abstracts and bodies of texts of refereed journal articles published in English. The keywords selected are closely aligned with humanitarian logistics/supply chain models for medical and healthcare products in humanitarian and disaster emergencies/disasters in Africa. Selected keywords identify articles that are focused on typical logistics and supply chain activities undertaken by the responsible public and private sector agencies for the provision of medical and healthcare products and charged with the role of planning for, preventing, leading, coordinating, and responding to disasters and other emergencies with a focus on healthcare.

Selected keywords also target articles focused on activities such as the logistics of disaster response and emergency relief delivery, and methods. Hence, the selection strategy for the keywords was aimed at ensuring maximum capture across the range of literature and all functional activities of logistics and supply chain management. Also, a rationale for choosing the keywords is that they are the same keywords used by authors in many published refereed articles on humanitarian logistics/supply chain models for medical and healthcare products in humanitarian and disaster emergencies/disasters in Africa. Hence, the increased likelihood that selected keywords will capture most or all relevant articles in the disaster databases searched. 
Some compound keywords were also used to broaden the search as well as words that are often used interchangeably such as 'disaster', 'emergency', 'distribution,' 'sourcing,' 'delivery,' 'distribution,' 'logistics' etc. It may be said that the English language literature on this topic is scant and mostly relates to operations research (OR), operations management (OM), management, social sciences, humanities, and medicine, however, no attempt is made to present all that has ever been established by research or published. The compound keywords are summarized in Tables 1 and 2.

[TABLE 1 HERE]

\section{[TABLE 2 HERE]}

\section{[FIGURE 1 HERE]}

In addition to the compound keywords in Table 1 and 2, three other expression were use including "logistics models of distribution", "emergency healthcare products", and "Medical disaster relief".

\subsection{Databases searched and articles found}

This subsection shows the databases searched using the keywords adopted in Tables 1 and 2 and the number of uptake of articles is summarized in Table 3.

\section{[TABLE 3 HERE]}

\subsection{Number of studies selected for exclusion and inclusion}

This subsection and Figure 1 shows the number of studies selected for exclusion and inclusion using exclusion and selection criteria.

\subsection{Summary of the research process}

Sub-section 3.4 summarizes the research process undertaken and the time research tasks were completed (see Figure 1).

\section{Search of databases completed.}


[Type here]

A total of 12,058 articles were retrieved from 13 databases using relevant keywords. After the removal of duplicates, 5582 articles were retained.

\section{Screening of titles completed.}

A screening of the retained articles based on their titles resulted in the exclusion of 5456 articles (126 articles were retained).

\section{Screening of abstracts completed.}

Abstracts of the resulting 126 articles were read and screened. Studies were retained if they reported on logistics models (31 studies were retained).

\section{Screening of full texts completed.}

The full-text of the retained 31 studies was reviewed, and 26 articles were further excluded (five studies were retained). Finally, five studies evaluating and reporting on logistics models for sourcing, delivery, and distribution of medical and healthcare products for humanitarian emergencies from 1990 to 2018 were retained.

\section{Manual search.}

A manual search of the bibliographic references of the final retained articles identified additional two studies thereby giving a total of 7 studies. The project is completed in approximately 18 months as shown in Table 4.

\section{[TABLE 4 HERE]}

\section{Synthesis and discussion of findings}

There are very limited numbers of published academic articles on humanitarian logistics models for medical and healthcare products in humanitarian emergencies in Africa. However, our review only extracted seven relevant studies evaluating and reporting on logistics models for sourcing, delivery and distribution of medical and healthcare products for humanitarian emergencies from 1990 to 2018 based on our inclusion criteria. This enormous research gap demonstrates clearly that this whole area is ripe for additional research. More so in view of the importance of individual and public health and wellbeing as well as the ease of global spread 
of infectious diseases and pandemics.

The literature review shows that (1) there are no qualitative or empirical studies in the area, and (2) five of the seven articles included in the review were quantitative, and only two studies were non-mathematical qualitative models.

\section{A. Mathematical models}

The five mathematical models found focused on:

(1)An earthquake emergency context where required relief items are expected to be supplied from international and national sources based on an intermodal relief item distribution model involving sea and land transportation with identified road vulnerabilities. Maritime transportation if suitable allows massive amounts of items to be transported at a time. It also allows for the use of two independent sources of supply (a) international, and (b) coastal/national transportation of items where such intermodalism is possible. However, the disadvantage is that maritime transport is slow and may not always be available to be used (for instance due to lack of handling equipment at ports, or damage to ports and their entrances). Also, maritime transportation is often heavily reliant on weather (Ozkapici et al., 2016).

The sea-basing concept used by some militaries is also suggested (Ozkapici et al., 2016). Seabasing involves permanently storing emergency supplies at sea in anticipation of an emergency closely and rapidly providing supplies to demand areas from such sea-based stockpiles. While the use of maritime transportation and sea-basing provides some flexibility for humanitarian logistical activities, sea-basing is expensive whether supplies are ultimately used or not, and require continuing maintenance.

The scheduling of medical teams and provisioning of medical supplies in an emergency where a medical team is required to make visits to several hospitals in a predetermined sequence to perform on-site operations and surgeries. This phenomenon is giving rise to a scheduling problem that involves the timely dispatching of supplies from stored and pre-positioned distribution centers to hospitals in coordination with the scheduling and arrival of medical teams that would use them to service patients (Lei et al., 2015). This approach assumes that there are adequate resources to pre-store and pre-position such supplies. The same weaknesses like sea-basing can be seen in this case - expense. It also does not consider the issue of transportation or transportation hindrances in delivering both the medical teams and their 
supplies (Lei et al., 2015).

The supply chain network of a single organization, such as a major health organization, corporation or government that aims to manufacture a particular product at several possible manufacturing plants, have it in storage, if needs are, and distribute it to the demand points (Nagurney et al., 2012). The model assumes that the organization is completely aware of the total costs associated with the various operational supply chain network activities (e.g., manufacturing, transportation, and distribution), knows existing volume capacities of the links, and is interested in identifying additional capacity outlays, production amounts as well as shipment values (Nagurney et al., 2012). This phenomenon is so that demand is satisfied with associated penalties if required demand is not exactly met for any reason.

As an option, the organization may choose to outsource manufacturing, storage, and delivery of the product at a negotiated fixed price and with capacities of such suppliers fixed and known (Nagurney et al., 2012). The model thus provides 'optimal' capacity enhancements as well as 'optimal' volumes of product flows to minimize total cost. This model is highly theoretical and inflexible for instance as it is unlikely that humanitarian organizations (or governments) would be manufacturing medical and healthcare products (Nagurney et al., 2012). Also, the optimal capacities of supply chain network activities will be dynamic and fast changing due to the changing dynamics of an emergency, and corresponding changes in demand.

(2)The delivery of product from neighboring regions and countries if proximal to the emergency site. However, future shortages in those supplying regions may incur (Rottkemper et al., 2012). Hence, the focus is on an integrated relocation and distribution planning approach that considers current demand and possible future developments regarding demand (Rottkemper et al., 2012). Minimization of operational cost and unsatisfied demand is the overriding objective (Rottkemper et al., 2012). However, more often than not, international humanitarian organizations source and import their supplies from their home countries into the host country as supplies may not be available in similar neighboring developing countries or regions.

(2)Cost minimization within a system-optimization perspective and captures rigorously the uncertainty associated with the demand for critical products such as vaccines, medicines and medical equipment at various demand points (Nagurney et al. 2010). This model by Nagurney et al. (2010) could be used for the production and delivery of critical products (vaccines, 
medicines, and medical equipment) at minimal cost to satisfy the demand at various demand points, given associated penalties for under-supply (Nagurney et al. 2010).

\section{B. Non-mathematical qualitative models}

The two non-mathematical qualitative models found focused on:

(1)An instantly built supply chain network model in the random occurrence of an emergency by international emergency relief actors. The network model involves a range of actors such as non-governmental organizations, governments, military, aid agencies, contractors, suppliers, logisticians, local community representatives, donors and others. It focuses on actors understanding how demand evolves during the time and how the flows of funding, goods, and personnel should be managed over time. The model is overly broad-based and generic. It also tends to do everything from disaster preparedness to emergency response, supply chain management to inventory and many more; and

(2)A review of the literature on logistics in complex political emergencies such as war and conflict and attempts to develop a generic supply chain management framework for health care goods provided as humanitarian assistance in war and conflict situations to enable improvement of the effectiveness and efficiency of humanitarian assistance programmes. The review includes a comprehensive and broad framework for supply chain management.

The summary of all quantitative and qualitative studies is represented in Figure 2 below.

\section{[FIGURE 2 HERE]}

\section{Proposed logistics model}

\subsection{Logistic performance criteria}

An overall assessment of the seven models shows that they each have limitations and may not be effective based on published logistics performance criteria. Logistics performance criteria can be classified into two: (1) effectiveness (how well set goals are met) and (2) efficiency (productivity, capacity utilization, and performance) (Mentzer and Konrad, 1991; Oloruntoba and Gray, 2009). It is also important that assumptions underlying the evaluation of logistics 
performance be set based on the goals of the organization - i.e., saving lives and reducing suffering and rapidly containing infectious diseases to its origins when appropriate (Mentzer and Konrad, 1991; Oloruntoba and Gray, 2009).

The peculiar context of emergencies and medical, healthcare products may mean that lowering costs may not be top priority relative to the criteria of effectiveness. For example, how many goods delivered in a certain time, how many goods delivered in good order undamaged? How many recipients were served on time? Nevertheless, overall considerations in logistics performance analysis should include the short and long run ratio of costs to effectiveness and 'customer' service. The 'customer' here is the recipient of medical products (Mentzer and Konrad, 1991; Oloruntoba and Gray, 2009).

Overall, one major element of logistics performance is transportation productivity. Transportation measures would include labor, equipment, transport energy consumes, transit time, loading time, and unloading time. Another major area that determines logistics performance is warehousing labor, product receiving, product storage, putting away, replenishing, picking, packaging and (re)labeling, facility utilization per square foot, and material handling equipment utilization and idle time. All these, of course, may be outsourced to an external logistics service provider who will undertake these tasks on behalf of an organization for a service charge. Overall organizations should always use logistics performance measures that are relevant to the goals of the organization. They should collect accurate and valid cost data to help them measure their performance as regards comparing the resources used against the goals achieved (Mentzer and Konrad, 1991; Oloruntoba and Gray, 2009). A key determinant of logistics performance is achievement of transportation productivity performance criteria as shown in Figure 3.

\section{[FIGURE 3 HERE]}

\subsection{Proposed logistics model}

A suggested model would have two phases focused on (1) pre-emergency planning and preparedness activities, and (2) activities undertaken during an emergency (Figure 5). The planning and preparedness phase must ensure strategic actions for preparedness and anticipation such as collection and analysis of baseline data and demographics as well as 
forecasting of various types of demand for target African countries. These could include population figures for various groups, number of accessible hospitals, health centers, and public health laboratories. In addition, in this planning phase, the key contacts and related details (phones, emails) in the target countries should be collected.

The first phase must be focused on planning and strategy for example, within the context of the specific goals of the organization as well as the context of the political and infrastructure features of the target developing country. Planning activities must also consider that logistics must fit in with and be coordinated with pre-existing systems and processes of the host nation and government.

\section{[FIGURE 4 HERE]}

Logistics activities must be executed in coordination with host nation political support and host nation health and medical authorities taking into account the complexity of factors affecting medical and medical relief logistics and supply chains as summarized in Figure 4.

Furthermore, effective logistics planning must consider local communities. Local leaders should be consulted, and their inputs and suggestions are taken into account in planning and implementing a logistics model given their local knowledge and legitimacy. The second phase when there is an emergency is when the model is implemented, and considerations must be given to:

\section{A. The nature of the medical emergency}

The nature of the emergency such as earthquakes, hurricanes, tornadoes, chemical leaks, terrorist attacks will influence the type of medical supplies required by the affected country. It could also be high rates of infectious and communicable diseases such as measles or pandemics such as Ebola or Malaria. Overall, outbreaks of communicable diseases should be expected in large populations especially when they live in crowded and poor sanitary conditions (e.g., Lassa fever).

\section{B. Agility and responsiveness}

The model itself must be quick to respond to demand by being agile and responsive. Agility is the ability to thrive and prosper in an environment of constant and difficult to predict change (Maskell, 2001). Agility is about responsiveness and mastering turbulence (Van Hoek et al., 
2001). Responsiveness in logistics arises out of an organization-wide capability, which embraces flexible organizational structures, information systems, logistics processes, and flexible mindsets (Christopher and Towill, 2000). An example of activities that result in a prompt logistical response includes coordination with relevant stakeholders and actors such as transport companies or host government agencies. For instance in the shared use of assets, equipment, or resources such as aircraft and trucks.

\section{Inventory and sourcing}

An effective model should maintain capacity flexibility to buffer against demand/supply uncertainty. For instance, applying effective demand-led inventory management in responding countries through the concept of postponement may be a cost-effective substitute for expensive pre-positioning. Logistics postponement may enable the assignment of medical and healthcare goods to be rapid. Such supplies may be held in responding countries with pharmaceutical suppliers and medical and healthcare product manufacturers through pre-supply agreements or memorandum of understanding to supply. Such supplies are held upstream as generic strategic inventory. The supplies are then transported and distributed according to the emergency needs of the end users in Africa when required. The postponement of the commitment of that strategic inventory to final delivery results in better use of more accurate needs analysis data from sites impacted by the emergency.

Hence, there is increased reliability and accuracy of information about recipients' immediate emergency needs. Maintenance of generic inventory may also help overcome market sourcing risks, including the risk of product obsolescence or market shortages. Selected suppliers themselves must be speedy, flexible, reliable and of high quality.

Generic stocks of supplies should be converted into recipient-specific deliveries in an agile way based on decision-making that derives from information input by local people. For example, information regards to the logistical accessibility, roads, terrain, weather, available materials handling equipment, (refrigerated or temperature controlled) facilities, depots, and warehouses, as well as culturally relevant information regarding the customs, practices, values, and religion of the community, can be collected from local people. The concept of postponement as a tactic for field level supply chain should have a positive impact on the speed of response, its flexibility, and agility in meeting the demand of end users. Maintaining capacity flexibility and responsiveness to buffer against demand/supply uncertainty may be undertaken 
by having two or three key suppliers to mitigate supplier risks as well as reduce costs.

\section{Delivery and distribution}

The number of people (or hospitals) requiring product is directly proportional to the amount of time consumed to reach them. Hence, in the early response stages of an emergency collaboration, coordination and collaborating are essential to save time. For example, local medical practitioners and public health specialists may be partnered with for rapid distribution of product and rapid administration of product to those who need it. Organizations require to engineer proper partnerships and coordination infrastructure before the emergency to be responsive to emergencies, which may require some upfront financial investment before the emergency.

Overall, the number of people in need of humanitarian medical assistance in Africa and other developing countries is significant. Such medical humanitarian assistance has a multitude of objectives towards different demographic groups that are relevant for logistics management. There are also many constraints related to medical/humanitarian organizations themselves, and the challenging context of developing countries. Furthermore, there are complexities associated with the enormous range of available medical and healthcare goods and their different categories as well as logistical management.

The peculiar vulnerability of many medical and healthcare products to 'use by dates', cold chain requirements, deterioration, and damage highlights the importance of quality assurance in the logistics process. The core focus of logistics performance should be efficiency and cost (use of resources), risk (damage in transit or storage) and effectiveness (customer service). Logistics planning and operations are determined at the pre-emergence and emergency phases as well as at the strategic, and tactical level respectively. In addition, the international and national distances to emergency areas are directly related to the level of risks and, in most cases logistics costs. Finally, the third aspect considers the criticality of individual items.

In addition, item selection may need to consider issues of standardization and reduction of variety, where to source product and whether to source within the country or internationally, and centrally or decentralized sourcing. The sourcing strategy further considers trade-offs between two or three big suppliers or use of multiple suppliers to reduce risk but increase costs and administrative burdens. 
Other issues to be considered include warehousing (international /home or in the field) as well as owning or renting of storage facilities or outsourcing from logistics service providers for a fee. There is also the trade-off between the objectives of effectiveness and efficiency.

Delivery and distribution determine criteria for using different channels (e.g., collaborating with local organizations and charities) and discusses effectiveness and customer service (of the recipient). The advantages and importance of collaborative planning and implementation with communities, their leaders, and host governments and others are discussed. A consideration for deciding on the stock positioning of items is proposed (e.g., with suppliers as pre-agreed, or inhouse).

\section{[FIGURE 5 HERE]}

\section{Dissemination to stakeholders and implications}

In section six, we discuss how findings of the project may be disseminated to stakeholders so that the knowledge generated meets its purpose, and indeed benefits important stakeholders and practitioners economically, socially, sustainably as well as in the areas of education and public policy in society. First, dissemination has already taken place through an interim and a final report to HI2 (i.e. Oloruntoba et al 2018). Other potential strategies for dissemination for stakeholders include:

\section{Outside Africa}

\section{$\underline{\text { Conferences and workshops }}$}

The use of public health, logistics and humanitarian conferences, workshops, seminars, and colloquiums is one strategy that could be adopted. These could be practitioner-oriented meetings that are attended by humanitarian non-governmental organizations (NGOs), donors, grantors, charities and others. For scholarly and research audiences a refereed conference presentation at a suitable conference such as a logistics, public health or humanitarian conference may be of value. In addition, a manuscript submitted to a logistics or other appropriate journal may be useful to disseminate findings to scholars and researchers. 
[Type here]

\section{Inside Africa}

Potential dissemination strategies include:

\section{$\underline{\text { Theatre and drama }}$}

Theatre is often used in health promotion, education and the training of health professionals in African countries, and has proven of value. Role-play and other drama strategies have been successfully used to support training and professional development of healthcare workers. Applied theatre may be used and performed to an invited public audience. The live performance of findings serves to engage the audience and concretize, rather than abstract, the findings, knowledge, and experiences of the research project. Theatre and drama can help transform social understanding more than textual presentation, as it challenges the academic privileging of written text. Theatre is also a focal point for audience members to discuss their own experiences of topics. It fits the critical social science approach that research should empower participants to change the context in which they operate or the way they behave.

\section{$\underline{\text { Training kits }}$}

To disseminate the model to stakeholders, advocate for change, and facilitate adoption and usage; the media, program managers, health professionals, public officials, and public health bureaucrats could be identified and targeted with the training and development kits used by officials in Ministries of Health.

\section{$\underline{\text { Media }}$}

Placement of summary findings in national and regional health-related media, periodicals, and publications could be of value in dissemination given the precisely targeted readership.

\section{$\underline{\text { Websites }}$}

Non-technical policy report, policy briefs and summary PowerPoint slides that summarize findings may be disseminated through relevant websites with links to regional stakeholders such as UNICEF (United Nations Children and Educational Fund), WHO (World Health Organization), DFID (Department for International Development), ODI (Overseas Development Institute), USAID (United States Agency for International Development), and others. 
[Type here]

\section{$\underline{\text { Policymakers }}$}

Humanitarian, disaster management, public procurement, and public health/epidemiology policymakers could also be targeted.

\section{$\underline{\text { Libraries }}$}

Many universities and high schools now have more library resources that can be used such as the Open Archive Initiative. The Open Archive Initiative compliant institutional repositories promise to provide greater access to resources and publications.

\section{Summary}

There is limited published academic literature on humanitarian logistics models for sourcing, delivery, and distribution of medical and healthcare commodities for humanitarian emergencies in Africa unlike subjects such as transport. Hence, papers that focus on sourcing, delivery, and distribution in the context of medical and healthcare commodities, as well as allied inventory management and warehousing studies, are needed. While the project does not present a complete solution, which suits every organization in every context or emergency, the presented model allows addressing core issues of logistics (sourcing, delivery, and distribution). The outlined logistics model can serve (medical) organizations as a starting point for developing their strategic framework for medical and healthcare logistics for developing countries given the peculiar goals and resource constraints of developing countries. The model may also be used for developing operational plans for a given emergency or used for analysis of logistics systems, processes and services of medical/humanitarian organizations for determining shortcomings and improving them. 


\section{References}

Armstrong-Mensah, E. A., \& Ndiaye, S. M. (2018). Global Health Security Agenda Implementation: A Case for Community Engagement. Health Security. 16 (4), 217-223.

Awan, Z. and Rahman, Z., 2010. Supply chain designs for humanitarian relief.http://www.divaportal.org/smash/record.jsf?pid=diva2\%3A327029\&dswid=9351\#sthas h. HpfbetVF.dpbs (accessed 12 June 2017) (M.Sc. Thesis).

Balcik, B., Bozkir, C. D. C., \& Kundakcioglu, O. E. (2016). A literature review on inventory management in humanitarian supply chains. Surveys in Operations Research and Management Science.

Bradshaw, D. (2017). Epidemiology in Public and Global Health. Epidemiology.

Buatsi, P., and Mbohwa, C. (2014). The journey to humanitarian supply network management. In Humanitarian Logistics: Meeting the Challenge of Preparing for and Responding to Disasters. Kogan Page Publishers.

CDC (2016), Center for Disease Control and Prevention Division of Global Migration and Quarantine - International Border Team https://www.cdc.gov/ncezid/dgmq/index.html (accessed 03/06/2018)

CDC (2017), Center for Disease Control and Prevention. The 2014-2016 Ebola Outbreak in West Africa. https://www.cdc.gov/vhf/ebola/history/2014-2016-outbreak/index.html (accessed 12/06/2018).

Çelik, M. (2016). Network restoration and recovery in humanitarian operations: framework, literature review, and research directions. Surveys in Operations Research and Management Science, 21(2), 4761.

Comes, T., Bergtora Sandvik, K., \& Van de Walle, B. (2018). Cold chains, interrupted: The use of technology and information for decisions that keep humanitarian vaccines cool. Journal of Humanitarian Logistics and Supply Chain Management, 8(1), 49-69.

Christopher, M. and Towill, D. R. (2000), Supply chain migration from lean and functional to agile and customised. Supply Chain Management: An International Journal, 5 (4): 206-213.

Dufour, É., Laporte, G., Paquette, J., and Rancourt, M. È. (2018). Logistics service network design for humanitarian response in East Africa. Omega, 74, 1-14.

EM-DAT (2017). EM-DAT- The International Disaster Database. URL http://www.emdat.be/ Retrieved: 23/08/2018

Findlater, A., \& Bogoch, I. I. (2018). Human Mobility and the Global Spread of Infectious Diseases: A Focus on Air Travel. Trends in Parasitology. 34 (9), 772-783.

Galvani, A. P., Fitzpatrick, M. C., Vermund, S. H., \& Singer, B. H. (2017). The Fogarty Imperative: The Importance of the Global Health Training Deemed Expendable by the 2018 White House Budget. Science (New York, NY), 356(6342), 1018.

Heaslip, G., Kovács, G., \& Haavisto, I. (2018). Cash-based response in relief: the impact for humanitarian logistics. Journal of Humanitarian Logistics and Supply Chain Management, 8 (1): 87-106. 
INFORM (2015), Index for risk management: Results 2015; 2015. http://www.informindex.org/ (accessed 23/08/2018)

International Border Team Website (2018), Centre for Disease Control - Division of Global Migration and Quarantine - International Border Team. https://www.cdc.gov/ncezid/dgmq/index.html (30/8/18)

Jalloh, M. F., Robinson, S. J., Corker, J., Li, W., Irwin, K., Barry, A. M., ... \& Sellu, M. (2017). Knowledge, attitudes, and practices related to Ebola virus disease at the end of a National Epidemic-Guinea, august 2015. MMWR. Morbidity and mortality weekly report, 66(41), 1109.

Kaner J, and Schaak S.(2016), Understanding Ebola: the 2014 Epidemic [PDF 486KB]. Globalization and Health 12: 53.

Koufteros, X., Mackleprang, A., Hazen, B. T., \& Huo, B. (2018). Structured literature reviews on strategic issues in SCM and logistics part 1. International Journal of Physical Distribution \& Logistics Management, 48(3), 202-204.

Lei L., Pinedo M., Qi L., Wang S. and Yang J. (2015), Personnel scheduling and supplies provisioning in emergency relief operations. Annals of Operations Research, 235 (1):487-515.

Maskell, B. (2001), The age of agile manufacturing. Supply Chain Management: An International Journal, 6 (1): 5-11.

McCoy, J. (2008). Humanitarian response: improving logistics to save lives. American Journal of Disaster Medicine, 3 (5): 283-293.

Mentzer, J. T. and Konrad, B. P. (1991), An efficiency and effectiveness approach to logistics performance analysis. Journal of Business Logistics, 12 (1): 33-49.

McGuire, G.A. (2006), Development of a supply chain management framework for health care goods provided as humanitarian assistance in complex political emergencies." $\mathrm{PhD}$ diss., WU Vienna University of Economics and Business (accessed 12 June 2017).

Nagurney, A., Yu, M. and Qiang, Q. (2011), Supply chain network design for critical needs with outsourcing. Papers in Regional Science, 90 (1):123-42.

Nagurney A, Yu M, Qiang Q. Multiproduct humanitarian healthcare supply chains: a network modelling and computational framework, 2012. Proceedings of the 23rd Annual POMS Conference, Chicago, Illinois, April 20-23, 2012. Available at SSRN: https://ssrn.com/abstract=1636294 or http://dx.doi.org/10.2139/ssrn.1636294 (conference paper) (accessed 12 June 2017).

Oloruntoba, R. and Gray, R. (2009), Customer service in emergency relief chains. International Journal of Physical Distribution and Logistics Management, 39(6): 486- 505.

Oloruntoba, R (2018), A systematic review of humanitarian logistics models for medical and healthcare products in humanitarian emergencies in Africa. Final project report of a seed corn funded project by the Humanitarian Innovation Initiative (HI2) The Watson Institute for International and Public Affairs, Brown University, USA. August. 
Oloruntoba, R. \& Ramaswami, S. (2018), A proposed framework of key activities and processes in the preparedness and recovery phases of disaster management. Disasters: The Journal of Disaster Policy and Management, 42 (3), 541-570.

Ozkapici, D.B., Ertem, M.A and Aygüneş, H., (2016), Intermodal humanitarian logistics model based on maritime transportation in Istanbul. Natural Hazards, 83 (1):345-64.

Overstreet, R. E., \& Hazen, B. T. (2016). Tips for conducting high-quality reviews. The International Journal of Logistics Management, 27(2) (Editorial).

Rottkemper, B., Fischer, K and Blecken, A. (2012), A transhipment model for distribution and inventory relocation under uncertainty in humanitarian operations Socio-Economic Planning Sciences, 46 (1): 98-109.

Save the Children (2015), A Wake-up Call: lessons from Ebola for the world's health systems https://www.savethechildren.org.uk/content/dam/global/reports/health-and-nutrition/a-wakeup-call.pdf (accessed 12/06/2018)

Stoddart, G. L., \& Evans, R. G. (2017). Producing health, consuming health care. In Why are some people healthy and others not? (pp. 27-64). Routledge.

Tranfield, D., Denyer, D. and Smart, P. (2003), “Towards a methodology for developing evidenceinformed management knowledge by means of systematic review", British Journal of Management, Vol. 14 No. 3, pp. 207-222.

Van Hoek, R. I. (2001), The rediscovery of postponement a literature review and directions for research. Journal of Operations Management, 19 (2):161-184.

WHO (2006), World Health Organization. Quality of care: a process for making strategic choices in health systems. http://apps.who.int/iris/bitstream/handle/10665/43470/?sequence=1 (accessed $31 / 8 / 18)$.

Wolicki, S. B., Nuzzo, J. B., Blazes, D. L., Pitts, D. L., Iskander, J. K., \& Tappero, J. W. (2016). Public health surveillance: at the core of the Global Health Security Agenda. Health security, 14(3), 185-188.

\section{Suggested readings}

Battersby, A. 1985. How to assess health service logistics with particular reference to peripheral health facilities. Geneva: World Health Organization.

Battersby, A. and Garnett, A. 1993. How to estimate warehouse space for drugs. Geneva: World Health Organization.

Dörner, G. (ed.). 1992. Management of drug purchasing, storage and distribution. Manual for developing countries. 3rd ed. Aulendorf: Cantor.

Quick, J. D. (ed). 1997. Managing Drug Supply. 2nd ed. West Hartford: Kumarian.

Shawkey, P., and Hart, C. 2003. Logistics' Contributions to Better Health in Developing Countries. Ashgate: Aldershot. 